\title{
Challenges of Implementing Consortium Strategy in Development Projects at ViAgroforestry, Kenya
}

\author{
Catherine A. Osoo \\ Impact Research and Development Organization \\ Vincent N. Machuki, PhD \\ School of Business, University of Nairobi, Kenya
}

Doi:10.19044/esj.2019.v15n1p151～ＵRL:http://dx.doi.org/10.19044/esj.2019.v15n1p151

\begin{abstract}
Consortium strategy involves an arrangement in which organizations develop, utilize and amalgamate structures, cultures, and operational systems to support competitiveness in delivery of service in a dynamic environment. This study sought to investigate challenges of implementing consortium strategy and measures to mitigate the challenges at ViAgroforestry, Kenya. Through a case study design both primary and secondary data were gathered through personal interviews and analysis of relevant documents respectively. Content analysis was used to analyze data. The study established that, both internal and external factors affected effective consortium strategy implementation at ViAgroforestry. The external factors that affected strategy implementation included social-cultural, political, economic, and technological factors. The internal factor included leadership and management styles, competency of employees among the partner organizations, lack of employee commitment to consortium operation, lack of adequate financial resources, unclear implementation guidelines and inconsistency in deployment of employees to support consortium. The mitigation measures to deal with the challenges include building employee competencies and confidence, setting up and reinforcing clear guidelines for selecting, recruiting and exiting partners in the consortium, mobilization of adequate financial resources, enhanced integration of Information Communication Technology (ICT) within the operating systems, and democratic style of management among partners. It was recommended that ViAgroforestry, Kenya should align organizational structure, provide adequate resources, build employee competencies and set and reinforce clear guidelines for operations while integrating ICT in its operations for effective consortium strategy implementation. In view of the limitations of the study, further research has been suggested on evaluating performance of consortium strategy implementation at ViAgroforestry, Kenya.
\end{abstract}


Keywords: Implementation of Consortium Strategy, ViAgroforestry-Kenya

\section{Introduction}

Strategy is an action plan that organizations pursue to achieve the set goals and objectives over long term period of time (Lynch, 2009).Both profit and nonprofit organizations develop strategies that can enable them advance their business objectives and goals. Determining the choice of strategy is one of the functions of top management of an organization (Pearce and Robinson, 2011). Consortium is defined as any formalized partnership arrangement committed to work within a given timeframe bringing together diverse competencies to better accomplish mutual objectives (Gonsalves, 2014). Consortium as a strategy is built around the principle of synergy which if not well implemented will be of no value to organizations (Hargrove and Hill, 2014). Like other strategies, consortium strategy faces different challenges at implementation because of the unique environments and conditions under which the implementation is done.

Consortia are one of the strategic choices that organizations seek to adopt in delivering services. Walther (2015) states that success or failure of consortium strategy revolves around inherent nature of the strategy itself (time consuming), the policies and support system of the organization (Catherine and Tom, 2015), alignment of the strategy to short term objectives; allocation of resources, fit between structure and strategy( Franco, 2014), staff and leadership capabilities (Chille, 2012; Wanjiru, 2015); communication, external influence and the organization culture (Christianson et al., 2012). The importance of this strategy can never be underestimated because even if it is formulated well, it will be virtually worthless if it cannot be implemented effectively (Lynch, 2009) and challenges facing consortium strategy implementation are not uniform; they vary from one consortium model to another(Beerkens, 2014).

Public Benefit Organization (PBO) is a nonprofit, organization that functions independently of the government. PBO's are organized on local, national and international levels to serve specific social or political purposes. PBO's rely on a variety of sources for funding projects, operations, salaries and other overhead costs. Fundraising efforts are important for PBO's existence and success as they operate on high annual budgets. This prompts them to adopt different modalities or mechanisms in order to operate sustainably in delivering their services. They adopt collaborative strategies like forming a consortium to bid for funds and cover wider geographical regions and deliver results that cannot be delivered by single organization. Funding sources include membership fees, profits from social enterprise 
ventures, private sector for profit, companies' philanthropic foundations, grants from local, state and federal agencies and private donations.

PBO's in Kenya are managed by the Non- governmental organizations coordination Board which was established by the Non- governmental organization coordination Act (Capt 11) of 1990 and commenced its business on June 15, 1992. The Board has the responsibility of regulating and streamlining the coordination of PBOs. The board is currently under the Ministry of Devolution and Planning. The Board was formed as a result of the recognition of the important role PBO's were playing in the overall development of the country. By then it had become apparent to the government that, for better organization of PBO activities, a separate body with full powers to register and coordinate their activities was necessary. PBO's engage in many programs which they deliver either directly or through consortium partnership with other organization, government and private sector.

Vi Agroforestry is an international non-political, non-religious and non-profit organization registered in Sweden as a foundation and in Kenya, Uganda, Tanzania and Rwanda as Public Benefit Organization (PBO).Vi Agroforestry has a vision of a sustainable environment that enables people in poverty to improve their lives. The organization addresses four thematic areas, Organizational Development and Partnership, Environment and Climate Change, Farm Enterprise Development and Gender /HIV Aids. Vi Agroforestry works with small scale farmers around Lake Victoria's catchment area in Kenya, Uganda, Rwanda and Tanzania. Since 2012, Vi Agroforestry participates in a new project in Malawi (Vi Agroforestry Strategy, 2011-2015).

$\mathrm{Vi}$ Agroforestry supports consortia of member based farmer organizations that have the aim of creating sustainable, democratic and well managed organization. Gradually from Swedish International Development Agency(SIDA) who is the main donor, the allocation for funding consortium partners has been increasing as funding for own implementation decreasing. There are 80rganisations in the consortium which have been implementing different projects within the Farmer Organization Agroforestry Programme (FOA) and Climate Smart Agriculture for Improved Livelihood project (CSAIL) respectively. They include Swedish Cooperative Centre (SCC) which offers advisory services to Sacco's in Kericho/Bomet County,Dairy Goats Associations of Kenya (DGAK) implementing dairy goat enterprise project. Kenya Rural Savings Society Union (KERUSSU) implementing the Business development for Livelihood improvement project targeting Sacco's, Western Tree Planters Association (WETPA) implementing commercialization of tree project among small holder farmers in Bungoma and Busia counties. Kimaeti Farmers Community (KFC) implementing Farm Enterprise for Livelihood improvement project in Bungoma County. Miriu 
Intergrated Organization (MIO) implementing Farm Business for Livelihood project in Rachuonyo County and Luchendi Cooperative Sacco implementing Financial services Empowerment in Elgeyo Marakwet.

ViAgroforestry is a PBO which has been in operation since 1982 and is implementing its' development projects through consortium, targeting the vulnerable, poor population especially small holder farmers. In as much as consortium strategy was considered an appropriate strategy for service delivery, it is prone to some challenges. These challenges are premised on business practice related to declining funding, overreliance on a single donor, competiveness in the PBO sector, changing development patterns, emerging changes in the organisational culture, policies and procedures, and emerging trends in the pro poor development approaches. They pose a serious threat to achievement of plans and sustainability.

In order to increase sustainability and local ownership, ViAgroforestry started implementing development projects by supporting local, regional and national Farmer Organisations in the year 2012 through consortium. There is a consortium steering committee represented by a leader from the consortium member organisations and is mandated to make decisions, pass resolutions and manage conflicts. It is led by ViAgroforestry which is the secretariat and is involved in coordinating the activities of the consortium including seeking for funding. In otherwise ViAgroforestry is the lead organisation. It works closely with the technical working group comprising of staffs in every thematic area of the projects being implemented by partners and can outsource for expertise from other stakeholders including the government line ministries. The organisations define their own objectives and activities, plan, implement, monitor and account for funds and ViAgroforestry provide technical expertise and administrative role (financial audits). In implementing this strategy, there are complex issues and the final outcome may not be optimal. This is observed in the 2013 audit report by KPMG whereby the organisations in the consortium had numerous financial accountability issues attributed to the absence (presence) of a clear guidelines on financial reporting, non- adherence to the guidelines, restructuring process which reduced the level of expertise support to partners, lack of organisational structure, lack of clear systems on human resource management and lack of clarity and consistency in organizational activities(ViAgroforestry, 2015).

Though many studies have been done on consortium strategy implementation challenges; Rebecca, 2012; Abuya, 2013; Hargrove and Hill, 2014; Maria and Marmol, 2014; there still exist a gap because their findings, recommendations and challenges may not be applicable to ViAgroforestry. Rebecca (2012) observed that operating in a consortium enabled organizations to create synergy in training staffs in management information systems. Abuya (2013) observed that inadequate resources (budgetary) stifled the ability to 
carry out strategic plans to the fullest, and leadership is core in providing direction and motivation. Maria et al. (2014) observed that the varying level of technological development and lack of congruence between consortium objectives and undertakings challenged operation. Hargrove et al. (2014) found that consortium provided small firms with tools to compete and strategic position of the partners enhanced. Kagumba (2014) found that poor communication inhibited stakeholder involvement in activities.

A critical review of the studies show that the studies were carried out using different methods, in different contexts, addressing different issues. Their findings generally highlighted some of the challenges that organizations face in implementing the strategies related to resource inadequacy, diversity in organizations in the consortium, lack of congruency between goals and activities. Their uniqueness compels organizations to align internally and externally to implement projects sustainably. None of the above studies highlighted the challenges specific to ViAgroforestry regarding consortium strategy implementation. Therefore, there still exist conceptual, contextual and methodological gaps that need to be addressed. This study was an attempt to address the aforesaid knowledge gap. What are the challenges of implementing consortium strategy in development projects at ViAgroforestry, Kenya? To address this question, the study sought to establish the challenges of implementing consortium strategy in development projects and the measures to mitigate the challenges.

\section{Literature Review}

Strategy implementation is premised on Institutional theory (Scott, 1995) the Mc Kinsey 7S model (Peters \& Waterman, 1982), Contingency theory (Fiedler, 1964) and Stakeholder theory (Freeman, 1984). These theories are embedded on the fact internal and external situations and competencies trigger organizations to adopt different mechanisms of doing things to attain stated goals and objectives.

Institutional theory focuses on the role of social influence for social conformity in shaping organizations actions. Organizations act to enhance their legitimacy by adopting strategies in adherence to institutional prescription hence reflect on the alignment of societal values and norms (Barney, 2010). The theory views organizations as means by which societal values and beliefs are embedded in organizations structure and expressed in organizations' ability to adapt to a changing environment through imitating more successful firms (Scott, 1995) in the same industry. DiMaggio and Powell (1983) as cited in Luthans (2011) stated that public or private organizations adopt formal structures, procedures and symbols that appear identical as managers find it easy to adapt to the changing environment faster by copying practices of a successful firm rather than developing new ones. 
Institutional theory is complemented by the McKinsey 7S model (Peters and Waterman, 1982), which provides a useful visualization of key components managers consider in ensuring that strategy permeates the day to life of an organization. These components are structure, strategy, systems, skills, style, staff and shared values. Structure relates to the organization chain of command. Strategy is the plan devised to maintain and build competitive advantage. Systems are the daily activities that staffs engage in to get work done. Shared values are the core values and beliefs of the company that can be seen in the corporate culture and general work ethics. Style relates to the leadership style adopted. Staffs are the employees and their general capabilities. Skills are the competencies possessed by employees working for the company (Lynch, 2009).

The Mc Kinsey 7s model posits that organizations are successful when they achieve an integrated harmony among three 'hard' 'S's of strategy, structure, and systems, and four 'soft' 'S's of skills, staff, style, and shared values (Peters \& Waterman, 1982). This model can be considered logical and rational in nature in the sense that logical view focuses on 'hard' aspects of the implementation effort (structure, systems, and strategy). Besides organization culture, less attention is paid to 'soft' aspects (skills, staff, shared values and style). This model pays little attention to context under implementation such as coaching and counselling, leadership, selection and socialization, employee motivation, power and politics. Implementing consortium strategy unavoidably raises questions of power within an organization (Ritchey, 2012).

Contingency theory postulates that there is no 'one best way' to lead an organisation, organise cooperation or make a decision (Fielder, 1964). However these actions are dependent (contingent) on the internal and external factors of an organisation to create the best fits in any given situation (Luthans, 2011). Contingencies for an organisation include technology, suppliers, competition, customers and distributors. The consequence is that a set of environmental conditions and organizational design characteristics may be found to be correlated as the best fit but organizations with inferior fits can be selected out by a process of survival for the fittest; some organizations can exist for extended periods with a poor fit because the industry is profitable enough to support a company operating sub optimally and others survive because the larger organization of which they are part of subsidizes them (Wanjiru, 2015).There is no single type of organizational structure equally applicable to all organizations, rather, organizational effectiveness and outcomes are the consequences of a fit or match between technology, environmental dynamism, the size of an organization and the information landscape (Luthans, 2011). The theory does not take into account risk-averting 
managers who do what others do regardless of existence of other potentially viable solutions.

The design of an organisation and its subsystem must fit with the environment and between its sub systems for an effective delivery of strategy in a partnership (Luthans, 2011). Therefore in designing an employee development training, communication and control systems (Anne and Tom, 2012), planning and decision making systems (Pearce and Robinson, 2011), motivating, leading and structuring the organization (Barney, 2010) the managers should bear in mind that situations under which the organizations exists coupled with stakeholders and societal influence may undermine pursuance of a strategy in a partnership. Consortium is inherently evolutionary in nature therefore subjective to the changes in the holistic environment (Updegrove, 2016).

Stakeholder theory postulates that an organization has a moral relationship with individuals, groups other than shareholders which possess moral status (Sternberg, 2004). Managers should explicitly articulate the shared sense of the value they create to stakeholders, clarify relationship regarding stakeholder's engagement, and create an enabling environment where everyone strives to deliver value (Ritchey, 2010). The theory argues that managers should make decisions that take the interests of the company's stakeholders into consideration (Freeman, 1984).

The stakeholders include individuals or groups who substantially affect the welfare of the firm. They include employees, customers, suppliers, debtors the government and distributors (Wharton et al., 2014). They stated that their interests must be integrated into the very purpose of the firm, with relationships managed in a coherent and strategic fashion to maximize on value which consortium strategy stands to achieve. There exist competing interests among the stakeholders and the theory fails to specify how managers can make tradeoffs among these competing interest hence making purposeful decisions to be abstract and, managers can be unaccountable for their own actions in an attempt to pursue a specific interest (Sternberg, 2004). Changes in the mix of stakeholders over time depends on the strategic issue, interest under consideration, changes in the operating environment and these attribute to diverse means of meeting the needs of the stakeholders (Carroll and Boletus, 2014).

\section{Implementation of Consortium Strategy}

Consortia are defined as mutually beneficial relationships built in a partnership between businesses of an industry (Pearce and Robinson, 2011). They are also referred to as models of collaboration unifying multi sectoral actors (individuals, institutions, or otherwise) which are exclusively independent of one another outside the context of the collaboration, to address 
a common set of questions using a defined structure and governance model (Tinoco and Sherman, 2014). Consortia are models which are increasingly used to implement multiple projects and conduct applied scientific research (Gonsalves, 2014). Jones, Evans and Kimberlee (2010) defined it as entities formed to allow individual participants to gain access to an opportunity that lies beyond their individual economic means or competencies. Consortia have been in existence for many years, particularly in industries where profitability and firm survival is driven by research and technology. They argue that while consortia is not new to the Public Benefit Organization sector, heterogeneous partner-types have recently emerged as models to execute development projects contributing to capacity enhancement, sharing ofi ideas, improving accountability and communication and better meet the needs of beneficiaries.

According to Brennan (2008) consortium can be classified as; informal networks where there is an informal arrangement between organizations and a partnership agreement may not exist; Contractual consortium with a lead organization whereby organizations forming a consortium agree to work through the 'lead organization'. In this case, the consortium is managed by a steering group which may include one or two representatives from consortium organizations with an agreement in place to guide operations. The lead organization applies for contract funding, manages the contract and distribution of funds to implement various projects on behalf of consortium members (Updegrove, 2010). A consortium is also formed with a new company called 'Special Purpose Vehicle' (SPV) formally constituted as an independent legal entity with an operating model agreed upon to source for funds and manage contracts and consortium members are shareholders. It is treated as an independent legal entity in all contract deals, the companies behind it do not need to be examined separately for this purpose (Walther, 2015).

In any consortium model, criteria for partner identification and recruitment, development of goals, due diligence and capability analysis (Ritchey, 2010), structure, roles and responsibilities, processes, communication guidelines, risk assessments, resource support should be developed by the members (Friedman, Lynette and LeBan, 2014). Most partners form consortia in anticipation of client requirements or in response to pre contract qualification criteria set by the client (Webster, 2010). Reasons advanced for the belief in the performance of consortia from the perspectives of the client and consortium members include creation of sustainable, collaborative relationships with suppliers in the public, private, social enterprise and voluntary sectors to deliver services, carry out major projects or acquire supplies and equipment (Wharton, Counihan and Strachan, 2014).The process of building and sustaining collaboration is ongoing and 
circular in nature beginning with developing a shared vision and ending with developing, implementing, and assessing the action plan.

Consortia and other forms of collaboration are not 'projects' by another name but are living relational arrangements which become (in) effective depending on how they are initiated and implemented (Updegrove, 2016). The underlying tenets of consortium strategy are that together, organizations can combine the capabilities of two or more service providers (Walther, 2015) through partnership to deliver larger and more complex contracts; cover wider geographical coverage (Alford and O'Flynn, 2012); allows for greater economy of scale and efficiency and effectiveness that cannot be achieve independently (Charity Commission, 2010). Partnership strategies are becoming increasingly popular as firms in all industries join with other organizations to promote innovation.

Consortium strategy implementation defines the manner in which an organization should develop, utilize and amalgamate organizational structures, control systems and culture that support competitiveness and improved performance (Ronnie, 2014). It is about competitive moves and the business approaches that are highly dependent on resource allocation to the different identified portfolios that managers can employ to grow businesses, attract customers, and conduct operations efficiently and effectively through risk mitigation to achieve results (Abuya, 2013). Consortia can compose of partners from a variety of sectors for example social enterprises with social enterprises or with voluntary organizations or involve a mixture of public, private sectors classified as single or multisectoral. Single-sector consortia allows for activities to focus on member firms' products which are homogeneous. Firms active in a specific sector are acquainted with each other and have greater knowledge of each other's businesses. In multi-sector consortia a wider range of products can be offered as firms are heterogeneous though a common image should be portrayed in service and product delivery (Friedman et al., 2014).

Hargrove et al. (2014) states that there are three models of consortia; contractual framework, where an agreement exist among the members to work together by setting out their legal rights and obligations (but without any additional legal entity); contractual framework with the additional feature of a joint steering group; the establishment of a jointly controlled company (special purpose Vehicle) as a separate legal entity through which the joint venture can be run. Deciding on which model to adopt depends on a number of considerations including nature of the project or need for flexibility in response to new developments and market opportunities. It should also be noted that the three models are not necessarily mutually exclusive but the approach given should be cautious as the features in both models may be similar (Ronnie, 2014). 
Consortium agreement should be effectively drafted (with the participation of every member) to fulfill multiple purposes within a project thereby ensuring attainment of project outcomes and members' participation .It sets out clearly the management and regulatory framework within which the project team members and stakeholders are to work specifying the roles, rights and responsibilities, and risks associated in the event of staff turnover (Wharton et al., 2014). Operational and management elements in the agreement should consider long term strategic elements and the likelihood of seeking further funding. Since collaboration may be created in response to a given set of contract needs, the desire to have reliable, trusted partners in place to be able to bid and deliver effectively implies the need to invest time to develop consortia collaborations (Tinoco and Sherman, 2014). Before entering into a partnership, firms should scrutinize the management accounts of key partners to enhance accountability.

\section{Challenges of Implementing Consortium Strategy}

The potential for greater realized returns through partnership does not come without challenges; recent studies have shown that partnerships have a modest 50\% success rate (Hargrove and Hill, 2014). Many partnerships arrangements face challenges due to lack of organizational capital, insufficient leadership commitment, and inadequate resources. These challenges are further exacerbated by undefined roles and responsibilities, non aligned capabilities, organizational diversity and cultural differences. Friedman et al. (2014) state that coordination of partnerships bring unique challenges in alignment of different organizational systems, programmatic directions, and cross-organizational values.

Financial resource management is necessary for procurement of services, equipment aiding successful implementation of consortium strategy (Alford and O'Flynn, 2012). However financial reporting, expenditure delegations and procurement rules are often vertically focused, creating challenges for complex cross-portfolio scenario inherent in consortia (Maria et al., 2014; Ronnie, 2014). A reduction or reallocation of financial resources for partners affect their ability to successfully deliver an initiative moreover forming consortia is inherently time consuming hence more costs are allocated towards building the initial systems. Consortia working push organizational borders and practices thus achieving standardization and harmonization takes time impacting on financial requirements (Wanjiru, 2015). When roles in a partnership are not prescribed, there may arise conflict and misunderstanding between firms within consortia with regards to design, management and financial control, where responsibility for the function can be seen to range from the SPV, as a whole, to different individual members. 
Resource management is the deployment of organization's resources in the most efficient way possible (Barney, 2010). Lack of adequate resources such as finance, inventory, human skills, raw materials and information technology affects consortium strategy implementation. Rummery (2002) as cited in Jones et al., (2014) states that resource management entails investing in resources as stored capabilities that can be unleashed as demanded. Lynch (2009) argues that human resource is the key resource on which to focus on in the implementation of an organization's business strategy. Strategy is formulated at the top, but implemented from the bottom, therefore inadequate and non-alignment of competent staff to actualize the strategy especially in the case of lead organization model of consortia afflicts successful consortium strategy implementation efforts (Ritchey, 2010).

Even though consortia may be perceived to bring benefits that cannot be attained by other routes, consortium working as with partnership working can present challenges (Ritchey, 2010). Partners in the consortium can be exposed to new risks, incur additional costs, encounter fundamental ideological differences due to diversity, setting of unrealistic goals, inconsistency and lack of clarity on roles, competition between partners, lack of information and experience, inadequate resources, cultural mismatch between organisations, power imbalances and leadership challenges can afflict consortium operations (Updegrove, 2016; Franco, 2014; Jones et al., 2014). They further argued that differing culture and values embedded in organizations can bring conflict and friction in some consortium models.

Carroll and Boletus (2014) identified organization's culture as an impediment to consortium strategy implementation. They defined organization's culture as the specific collection of values, norms, beliefs and attitudes that are shared by people and groups in an organization controlling their interaction with each other and with stakeholders. Culture is a key driver to organizational effectiveness and performance (Catherine and Tom, 2015). However, complexity in consortia breeds cultural diversity negating customer satisfaction and employee commitment to change (Friedman et al., 2014). They state that organizations carry along their individual history to the partnership, complicating integration and coordination which breeds rigidity to change amounting to conflict and lack of collective identity.

Abuya (2013) identified lack of common standards for reporting; different monitoring and evaluation practices; different leadership ideologies; restrictive policies and procedures; employee's resistance to change as some challenges inhibiting consortia operations. Under common standards approaches, Jones et al. (2010) concur that even though standardization drives quality, build coherence and reduce complexities of managing local systems, creating an interface between standard approaches and existing systems is normally a challenge in partnership. Developing reporting standards that are 
aligned with the partners' capacities in reporting can be challenging in consortia that are boundary-spanning with varying degrees of expertise in reporting practices expected by the lead organization or funder (Walther, 2015). Gonsalves (2014) states that restrictive policies and procedures regarding use of technology negate knowledge sharing challenging optimal participation of partners.

The institutional embeddedness of organizations provides opportunities as well as constraints for their behavior. This notion claims that the differences in the institutional environments where the organizations originate, can impact on cooperation in a negative way (Hargrove and Hill, 2014). These differences are frequently related to the historical conformance of organizations to their national institutional environment; organizational structures; procedures and routines that have emerged and have become institutionalized regarding adoption of ICT and innovations; procurement procedures and knowledge management (Chille, 2012). Poorly shared knowledge inhibits competency building and optimality of strategy. Beekens (2014) asserts that technology support institutional processes however structural arrangements in consortia impede its functionality.

Diversity is inherent to consortia. In fact, differences are meant to be a source of added value. If diversity is not appreciated for its development significance, the foundations of a consortium can be shaky (Maddrey, Gerland, Lee and Corapi, 2015). Difference in historical background of the consortium members concretes culture diversity that if not explored early inhibits adoption of common standards for reporting, monitoring and evaluation, and integration of Information Communication and Technology in projects operation (Gonsalves, 2014). Though standardisation drives quality, build coherence and reduce complexities of managing the consortium, integrating standard approaches to fit within existing diverse systems of organisations varied in contexts, is difficult.

When a consortium is incapable of successfully realigning its configuration to adapt to changes that occurs in member firms, tension is often experienced. Membership composition change over time, as others leave and others join. Therefore promotional activities aimed to recruit new members and harmonize common interests between the old order and the expectations of the new members (Franco, 2014). Propensity of member firms to collaborate is often occasioned by the management styles of the partners. Change in the ownership or at the top management level of a member firm can lead to resistance to adopt a corporate strategy (Douglas, Flinchbaugh, Kruse and Ohler, 2009).

Changes in the macro-environmental context (external) such as economic, politico-legal, social, technological and environmental (Charity Commission, 2010) impede consortia operations. Purchasing power depends 
on current income, savings, prices and credit availability, any change in the direction of the economies in the public and not for profits sectors present changes in financial operations of an organization (Walther, 2015), affecting revenue streams in the partnerships (Maria et al., 2014). The changing social environment compels organizations to align their social values, behaviors, attitudes lifestyle, work ethics, gender and social responsibilities to meet societal expectation. Meeting social expectations influence compatibility in delivery of services in a cooperation (Jones et al., 2010; Beerkens, 2014). Difference in environmental and demographic characteristics coupled with unanticipated changes in the government policies regarding taxation, cooperation legislation, environmental protection, and affect complementarities in performance of cooperation (Alford and O'Flynn, 2012).

\section{Measures to Mitigate Challenges of Implementing Consortium Strategy}

The use of virtual collaboration tools should be embraced to combat rising operational costs when covering a wider geographical area (Maddrey et al., 2015). A forum for sharing capabilities like online partner forums, inperson program reviews, conference presentations, and association meetings when adopted with relevant ICT adoption reduces cost. Organisations considering forming or joining a consortium should spend time to learn and ensure compatibility of values and norms in working. A shared value base forms a culture that fosters performance. Brennan (2008) states that integration among partner organisations required can only be achieved through trust.

Determining the rules of engagement is a mitigation measure. In the planning phase, partnerships are solidified and categorized (Wanjiru, 2014). In consortia, partnership can be informally and organically, others establish formal agreements using contract agreement materials for both understanding of roles and responsibilities sets collective expectations mitigating potential conflict during project collaboration (Douglas et al., 2009). Managing change is another way of dealing with challenges in consortium strategy implementation. Making adjustments to fit the change process in executing strategy and overcoming resistance is a milestone to strategic success. Employees and management should focus on the consortium objectives rather than individual objectives (Tinoco and Sherman, 2014). Fostering a collaborative culture requires coordination and inclusion through endorsing partnership as a strategic, organization-wide priority and promoting an objective, transparent partner seeking mentality across all levels.

Diversity is inherent to consortia. Exploring diversity in partnerships should be institutionalized and fostered (Webster, 2010). Understanding organizational restrictions and complexities in initiating or structuring partnerships bring clarity of roles, goals and objectives fostering value 
creation and performance (Ronnie, 2014).Organisations in the consortium should be alert to the changes in the external environment affecting the stakeholder relationship. Capacity development is cross cutting to implementing partners and stakeholders in developing organizational capacity.

Defining specifically what products or services the consortium will develop and the benefits expected is important. The consortium's goals and activities should be greater than what any of its individual entities could achieve on their own to warrant the work required to come together (Maddrey et al, 2015). Some organizations assume there is intrinsic value in combined scale and expertise, without articulating or testing what that really means. Therefore early in the planning process, consortia should define specifically what they plan to do together, when, with whom, and how to engage with one another both within and outside their own organizations (Anne and Tom, 2012).

\section{Methodology}

This study employed a case study design. A case study was appropriate as it allowed the researcher to focus wholly on the challenges facing consortium strategy implementation narrowing to ViAgroforestry Kenya as the unit of analysis. Yin (1994) as cited in Polonsky and Waller (2004), states that a case study is a method that allows an investigation to retain holistic and meaningful characteristics of real-life events such as organizational and managerial processes. It entails in depth investigation of an individual, group, institution or phenomenon and also analyzes comprehensively an institution with respect to the variables (Mugenda \& Mugenda, 2007). Case study design was preferred as it brought empirical evidence of the theoretical assumptions that emerged during the literature review. It has also been successfully used by researchers; Abuya, 2013; Hargrove et al., 2014 and Kagumba, 2014 in their studies.

The researchers used a structured interview guide for primary data collection. The structured interview guide consisted of open-ended questions aimed at obtaining information relevant to this study. According to Polonsky and Waller (2004), its development entails selecting the theme; defining all the aspects of the theme; formulating initial (open ended) questions; determining the kind of questions; determining the logical order of the theme/question; preparing the introduction and the end; and preparing the interview technical indications.

Data was collected from the 7 management team and 9 technical working group members of ViAgroforestry Kenya. In the management team there are 6 project coordinators and the country manager and his deputy totalling to 7 and 9 component heads forming the technical working group 
who also support consortium partners at various levels in relation to thematic areas. The guide was pretested for validity and reliability to 2 interviewees before being administered through personal interview to the top management and heads of technical working group of ViAgroforestry Kenya totaling to 16 interviewees. Secondary data was obtained from ViAgroforestry annual reports and publications, website, developed proposals and consortium agreements.

The data obtained were largely qualitative hence qualitative data analysis was used in form of content analysis. Content analysis involved observation and detailed description of objects, items or things that comprise the study (Mugenda \& Mugenda, 2007). Data collected was edited for completeness and consistency. The researchers selected unit of analysis based on the objectives of the study. Data were grouped and categories created as main category; generic category and sub category in order to increase understanding, thus interpreting which textual materials are to be highlighted with a highlighter and put in the same category.

\section{Findings and Discussion}

This section presents the findings and discusses the findings along the study objectives.

\section{Implementation of Consortium Strategy at ViAgroforestry}

In order to establish how consortium strategy is implemented at ViAgroforestry - Kenya, the interviewees were asked to state and explain how this happens. It was established that there exists a strategic plan that covers a period of 5 years and had been reviewed once in a meeting incorporating comments and views from the employees. The strategic plan spells out the vision, mission, goals and objectives to be achieved by the organization. The consortium has guidelines defining operations and spells out organizational structure, the partnership itself, consortium formation process, consortium agreement and the consortium operation process.

Before recruiting partners into the consortium, ViAgroforestry Kenya conducted an assessment to potential organization using a due diligence tool which is an improvement of octagon tool. The assessments involved visiting the organization's office and identifying its activities, in order to get the true picture of their status; Meeting the staff members, board members and officers of the organization; checking the key documents such as constitution, operating procedures, annual reports and audited financial reports. The team also engaged the external stakeholders' i.e. the community, local government and NGOs in the assessments to obtain the wider picture of the partner organization. 
The consortium organization structure exist whereby ViAgroforestry is the lead organization in charge of advisory and fund mobilization and; the steering committee as the supreme decision making body and the technical support. The steering committee is composed of the top leaders from the partner organization and is being led by an elected chairperson who provides overall leadership to the steering committee, ensures that programme objectives and expected outputs achieved; develop and approve policies to be applied for the programme implementation; and approve plans and budgets for the programme as submitted from time to time by the partners; monitoring the performance of the programme and making recommendations regarding improvements; reviewing and approving narrative and financial reports;. The technical working group led by a team leader provides support to the partners in the thematic areas defined by the programme and they present compliments to the steering committee and the secretariat which is ViAgroforestry who takes lead in sourcing for funds.

The study established that planning for the partnership operations involved the partners developing proposal within the programme thematic area through a standard template developed by ViAgroforestry with the support of ViAgroforestry staffs. The proposals are forwarded to the programme office for quality assurance and approval for funding for 1 year period. Before the funds were disbursed, the partners sign an agreement with ViAgroforestry accepting to comply to the rules and regulation.

The partners having received funds normally have a joint meeting where action plans are developed from the log frame and shared. Areas of technical support identified and shared by the technical working group. The planning meetings also offered an opportunity to gauge the adequacy of funds as per approved. The utilization of funds by the partners are often guided by the laid down procedures for consortium operation. Quarterly, semi annually and annually, the partners prepare reports for submission to ViAgroforestry regional office through ViAgroforestry, Kenya.

The study established that the partners build their own systems of monitoring and evaluation of projects performance in relation to the expected outputs. This monitory role was assigned to partners' staffs, who worked closely with the technical working group. The risks of non compliance to the stated procedures of operations were borne by the partners. The study established that the partners who did not measure up to the expected deliverables as stated in the guidelines were exited out of the consortium with resolutions passed at the steering committee meeting.

\section{Challenges of Implementing Consortium Strategy at ViAgroforestry}

Interviewees were interviewed to establish the challenges of implementing consortium strategy at ViAgroforestry, Kenya. They indicated 
that the challenges were both from the internal and external environments. The internal challenges were within the preserve of ViAgroforestry, Kenya while external challenges entailed factors emanating from consortium partners and the larger macro environment where Viagroforestry, Kenya does not have control over.

The study found out that poor organizational culture impeded consortium strategy implementation at ViAgroforestry, Kenya. Organizational culture is a set of shared values, beliefs, norms and attitudes often unwritten though taken for granted, that guide the employees towards acceptable and rewarding behavior. They indicated that different institutions in the partnership had different norms, values, attitudes and beliefs inherent in their institutions history which guided their operation. There was no common harmonized culture guiding day to day conduct and operations of activities in the consortium. Even though common values exist in the guidelines they were not shared across organizations. They said that ViAgroforestry, Kenya did not put in place mechanisms to enable staffs other than the technical working group to interact and view consortium as an all inclusive affair. This advanced a belief and perception that consortium was a vehicle to drop people home as partners aboard, rather an entity for mutual benefit. Moreover staffs perceived leaders of the consortium as 'village committees' not fit to share space with the elites hence no shared values in common. These contrasting attitudes and perception bred bad culture that negated harmonization of ideas. An interviewee said that;

"A factor that affected consortium strategy implementation was that we (staffs) were not provided by the consortium implementation guidelines articulating the principles and shared values neither do we attend those meetings"

The study established that the consortium organizational structure was complex, not clear and not well understood internally and externally negating consortium strategy implementation efforts. Organizational structure refers to the way an organization arranges people and jobs so that its work can be performed to meet its determined goals and objectives. They indicated that the complexity of the structure contributed to long procedures and bureaucratic processes in making key decisions during proposal development, approvals, signing of agreements, and disbursement of funds and subsequently work plan development. These long processes gave projects narrow margin or timeline for implementation thereby constraining consortium strategy implementation process. An interviewee indicated that;

"No, there hasn't been any change in the organizational structure to accommodate new projects only existing departments within the structure are added new responsibilities". 
The research found out that some of the institutional procedures, systems and policies for consortium implementation were not clear and therefore they were not well implemented. Systems, procedures, and policies refer to well laid guidelines, often standardized that inform and guide the operations of activities in an organization. The study established that internal policies and procedures such as human resource policy, financial guidelines policy, anti corruption policy, procurement policy as policies that were not revised with the inception of consortium strategy hence no coherency with the new strategy. Different partners undertook different projects contributing to complexity in development of standard reporting systems for all partners in the consortium negating quality assurance efforts. An interviewee explained that;

"Existing policies, guidelines, rules and procedure are not known to consortium members neither have they been revised to accommodate changes that consortium brought"

The study established that inadequate resources (financial and physical) coupled with delay in funds disbursement affected partner's effort to establish physical offices, undertake timely implementation of consortium activities and optimal use of resources. Resources are said to be tangible or non tangible assets that organizations require to facilitate its operations. Inadequacy of these resources was further aggravated by lack of sustainable measures to cushion the organization against funds delay or inadequate funding. The study found out that resource insufficiency affected mobility as motorbikes for field operations in the wider geographical area were few with restricted or limited fuel consumption, inaccessibility of office space for partners operation reducing their visibility and inability to implement activities and achieve results as planned. Bringing more partners on board also contributed to resource inadequacy. An interviewee stated that;

"Sometimes lack of resources challenge partners operation as I can budget for an activity and I am told that the funds are not there or the motorbike has broken down therefore I should reschedule".

The research established that there was no sufficient communication to stakeholders (line ministries in the government, community members and private sectors) regarding the consortium strategy implementation leading to conflict of interest during implementation. Stakeholders are individuals or groups who substantially affect the welfare of the organization. The research established that during the setting up of the consortium, stakeholders were called and briefed about the strategy but subsequently there hadn't been any effort employed by ViAgroforestry, Kenya to update them on the progress of its implementation. It established that of the business plans currently being implemented by partners under CSAIL project on different value chains, there hadn't been a substantive efforts to create linkage between the private sectors 
and the farmers for the purpose of forging business relationship due to lack of awareness at the market level. An interviewee stated;

"During follow ups and stakeholders forums I often meet tough questions, when consortium strategy was communicated; farmers went ahead forming groups in readiness to receive funds from Viagroforestry, Kenya. This hasn't been the case for most groups, so they say that SIDA gave ViAgroforestry money to give groups but there is no transparency in doing the same, which criteria was used".

The research established that the outcome, objectives, and expected outputs in the log frame were ambiguous and not clear. Outcome, objectives and expected outputs are the deliverables logically outlined in the log frame to be achieved by the organization, together they describe the projects theory of change. Particularly, the interviewees cited the output on lobby and advocacy as unclear and not within the technical capacity reach of the staffs within ViAgroforestry, Kenya and partners in the consortium to achieve. They said that the activities for the component of lobby and advocacy was a donor driven agenda and gauging the political environment, farmers had very little to influence any form of change within the donors prescribed timeframe. Moreover, generally some partners boundaries overlap leading to overlap during implementation of projects therefore distinguishing which partner has achieved a given output within a context was difficult. A community based organization may be targeted by two partners for the same output thus gauging the achievement limit for each partner may not be easy. An interviewee said that;

"The challenge is some outputs are not clearly understood by staffs and partners and these communities are close to each other".

The study established that consortium strategy implementation was affected by external factors emanating from the partners' internal operations and institutional structures. External factors are variables that cannot be controlled by ViAgroforestry Kenya. They take the form of political, legal, economic, socio cultural and technological factors. Political factors dictated the level of involvement of stakeholders in the consortium which due to the geographical coverage, their diverse interest could not be synergized. The interviewees said that inflation rates, direct taxes and indirect taxes, fluctuating dollar exchange rates affected the economic operating environment of the consortium. Changing trends in Information and Communication Technology drives the organization to train staffs on the modern data management systems such as the web based planning however resources and skills to acquire and manage them are inadequate.

Unforeseen political complexities such as riots and unrests restricted physical movement of staffs hampering implementation of some activities across the region. Poor infrastructure spread across the geographical regions 
targeted by the consortium negated follow up efforts and other operations. Government regulations and policies as advanced by the NGO council on accountability and transparency brought a shift in donor alliances and approaches diming funding opportunities. The research established that some communities targeted by the consortium have social values that impeded consortium operations e.g religious values(holding prayers on Thursday) restricting attendance of meetings as planned, gender perceptions (some men are not comfortable with women in the community holding positions like chairperson) and language barriers. Changes in donor approaches regarding implementation of projects and programmes were cited by interviewees as a challenge, non response to these approaches meant not meeting donor demands hence raising concerns on the level of competency in the consortium An interviewee stated external factors to include;

"The following external challenges were experienced during the period of strategy implementation; inflation rate affecting dollar exchange rate; government regulation and policies; inaccessibility of rural roads; legislative procedures".

The study established that the competency levels of some staffs to implement consortium strategy were wanting and this impeded consortium strategy implementation. Employee competencies are those traits, skills or attributes that employees need to perform their jobs effectively. Competencies always vary by job and position. They said that this was brought about by consistent layoffs of staffs with no deliberate efforts to employ some with the same competencies. In this case the interviewees cited that there existed a competency gap among the employees assigned to assist partners because there was no consistency in allocation of these duties to staffs hence a lapse in skill development relating to a particular thematic area. This was evident by back and forth revision of proposals in the last funding year and many areas of financial accountability issues and reporting indicated by the audit reports and. An interviewee observed that;

"Allocation of duties not based on competency leading to inefficiency of service delivery".

The research established that the top management of Viagroforestry, Kenya had not amicably played supported the strategy implementation by motivating staffs. Management support involves ways of making decisions and relating to subordinates. They said that the management had not been taking an active role to persuade staffs to embrace the strategy through rewarding and recognizing staffs that spent extra time in supporting the partners. They said that the management contributed to admission of some weak partners into the consortium without thorough assessment and feedback further weakening the partnership delivery competency. These weak partners had weak leaders making staffs spend a lot of time in strengthening their 
leadership skills. These leaders failed to embrace best practices stipulated in the consortium guidelines often leading to comingling of funds as exhibited by audit reports. This approach depicted a non consultation move and non adherence to stated guidelines relating to partnership admissibility. An interviewee stated that;

"Partners took a long time to formulate their policies and plans; weak leadership at partners' organizations; time consuming; capacity gaps among partners; took a long time".

The study found out that there was no inbuilt monitoring and evaluation system in place for monitoring consortium activities. Each partner monitored the progress of its own activities independently. Monitoring and evaluation is the periodic assessment of project activities to ascertain the gaps and address them adequately. Lack of proper monitoring and evaluation system in place as the interviewees said created a window for some partners to go off the track in performing some activities; Lack of this system contributed to making decisions without basis. For example, it was established that KERRUSSU LTD was not given adequate funds because of poor performance as per the audit report and this brought about issues as there were no quantitative basis in regards to the log frame. An interviewee said that;

"Each partner monitors its activities individually, there is no monitoring and evaluation staffs for the consortium".

Measures to Mitigate Challenges of Implementing the Consortium Strategy at ViAgroforestry, Kenya

The challenges of consortium strategy implementation were found to include; poor organizational culture, complex organizational structure, unclear and restrictive systems and procedures, resource insufficiency, poor communication, unclear objectives, output and activities, inadequate staff's competencies, poor management style and inappropriate system for monitoring and evaluation. Measures to mitigate these challenges were suggested by interviewees as discussed below.

On the challenge of organizational culture, the research established that a new culture should be reinforced within the system through rewarding behaviors, attitudes and conduct that promote and embrace new culture within the consortium. The employees should be encouraged to develop a culture of team work across departments to support the effective consortium operations. Staff retreats or team building events bringing together ViAgroforestry staffs, technical working group, steering committee and partners' staffs should be organized to foster and build positive collaborative efforts. They suggested that the different values, beliefs, attitudes, norms and perceptions should be harmonized to represent the consortium as a unit. An interviewee said that;

"All partners should work towards framing values, beliefs and attitudes that guide day to day undertaking of activities for example we 
(ViAgroforestry) are keen in keeping time during field follow ups but a partner organization like Miriu would always be ahead of time".

On the challenge of organizational structure impeding consortium strategy implementation, the interviewees stated that the structure of the consortium should be reviewed and made simpler to accommodate a wing that will be in charge of capacity building and resource mobilization function to enhance proper decision making and task allocation when it comes to developing proposals. It was suggested that the steering committee should also compose of the board of directors from the partner organizations because deliberations from the steering committee must be approved by the board before being implemented but the board was never represented in the consortium meetings. An interviewee said that;

"During consortiums meeting the current structure should be reviewed to accommodate board representation from the partners to harmonize sharing and decision making".

The study established that internal systems, policies and procedures should be availed, reviewed and updated in a participatory manner to accommodate staffs views and interest of the consortium. In particular, they indicated that the human resource manual on compensation and remuneration should be reviewed to accommodate changes especially for staffs who take time to offer technical advice to partners under the hospice of technical working group. They also suggested that the systems should be enhanced to ensure efficiency considering that some partners were spread in the wider geographical area and when systems of operations such as procurement and financial reporting systems were improved efficiency was guaranteed. This included enhancing the ICT system to be all inclusive. An interviewee said that;

"Avail the policies to all staffs and interlink the systems and procedures to save on time and be effective".

The study found out that the consortium should emphasize on the partners having resource mobilization function within their structure. This would ensure that the partners generate their own resources to complement consortium funding to ensure continuity of operations. They suggested that other than focusing on SIDA to fund the FOA programme; ViAgroforestry, Kenya should also diversify its funding base by writing concept notes to other potential funders. The customers who were the target group and shareholders could always influence the resource allocation process within the consortium thereby influencing the selection of proposals for investment in projects. It was also suggested that the secretariat which is Viagroforestry, Kenya, should come up with a resource allocation process model that would ensure that resources are adequately allocated depending on the demand and capacity to 
utilize with minimal wastages. The study established that this could only be achieved through proper planning. An interviewee said that;

"Resources could be sufficient if targets are realistic, sometimes people target highly with few resources".

The study established that communication methods, tools and systems should be improved for efficiency in consortium implementation. Other than meetings, emails and booklets, it was evident that other systems, methods and tools of communication such as video conferencing, use of Skype, open forums and staffs parties should be explored. They stated that if the employees were constantly informed and reminded on the strategic plans and roles clearly articulated and shared, their commitment and participation to strategy will be fully guaranteed. They suggested that management should hold stakeholders forums to communicate the progress of implementation. Specifically, they cited the CSAIL project implemented by consortium partners which the stakeholders kept on asking the staffs about. An interviewee said that;

"There is no enough communications regarding consortium strategy even inside here( within ViAgroforetry) except for a few; use other mechanisms not all attend those joint meetings".

The study established that the management should clarify the goals and objectives of the projects being implemented by the consortium to avoid duplication of activities and resources. They suggested that there should also be a proper demarcation of the target group with clear outputs aligned for achievement. This could be achieved through joint planning of activities, sharing of action plans and having debriefing sessions with the implementers. Overlapping activities should be identified and pointed out for improvement during review meetings to improve subsequent proposal development. An interviewee said that;

"There could be conflict but activities are always harmonized during planning meetings".

On external factors impeding consortium strategy implementation, the interviewees from Viagroforesty, Kenya suggested that there should be decentralization of non core operations so that the business practice could be viewed as one entity though well coordinated at partner's levels to avoid delays and extra costs especially in procurement of equipment and other assets. They suggested that the top management should invest in learning and borrowing best business practices from other stakeholders to minimize implementation costs. They indicated that social-cultural aspects of the population targeted by the consortium programmes' areas of operation affected consortium strategy implementation hence keen interests should be put in analyzing the spread of demographic aspects (age, sex, income level, average size of family, education level) of the target population to inform conceptualization of projects. An interviewee said that; 
"Analyze the target group before in relation to demographic traits at project concept building".

The interviewees suggested that other than the technical working group, other staffs capacities should be identified and built to enhance continuity in case of lay off and other disruptions like leave and emergencies. The competencies should be built around the thematic areas being implemented by the consortium partners. They also suggested that the management through appraisals should identify training needs through undertaking needs assessment for staffs and provide trainings based on the identified needs. An interviewee suggested that;

"Let all staffs be trained to gain knowledge equally to enhance support".

The study revealed that the management should embrace consultation and dialogue before recruiting partners to the consortium by utilizing assessment reports and involving technical working group representatives constructively. These assessments done to each partner represent the real picture and therefore the management should embrace the outcomes of the assessment to avoid weak partners being admitted to the consortium. It was suggested that partners should be admitted on the basis of synergy they would create in the consortium thus the management should adhere to the guidelines and not dictate the process.

"Management should consult while admitting some weak partners to the consortium because they don't understand the concepts easily".

The study found out that the consortium should develop inbuilt mechanism to monitor and evaluate their activities to ascertain whether the implementation was on course. This would contribute to standardized reporting and operations. They suggested that when the monitoring and evaluation reports were shared, the progress of the consortium operations would be gauged and gaps addressed adequately. This would also involve employing a monitoring and evaluation officer within the consortium. An interviewee said;

"There should be department, a system and somebody responsible for monitoring and evaluation".

\section{Discussion of Findings}

The findings of the study revealed that ViAgroforestry Kenya has a strategic plan in place spelling out the vision, mission, goal and objectives to be achieved within 5 year time period and there is a consortium of partners from different background and sector implementing FOA and CSAIL projects, ViAgroforestry Kenya is the secretariat. This in line with Mc Kinsey 7S model (Peters \& Waterman, 1982) which states that strategy is one of the seven internal components that an organization should posses in order to compete 
successfully. For a strategy to deliver intended results, strategy itself must exist. The study revealed that partners in the consortium are multi-sectoral and were identified and assessed based on their potential for collaboration, an argument that Jones et al. (2010) concur with.

The study also revealed that there are laid rules, policies and procedures that guide consortium operations and the partners in the consortium normally undertake joint planning meetings to review their log frames, to plan for activities and resource utilizations and also to share experiences. The research found out that there are operational guidelines, agreements that needs to be reviewed and internalized with time therefore a lot of time is needed for planning and reviewing and scrutinizing some activities every time as the partnership progresses with time. This is in line with Tinoco and Sherman (2014) who argued that time is a key factor in developing collaborations.

The study established that the consortium structure exist whereby ViAgroforestry is the lead organization and the secretariat to the consortium currently playing a key role in resource mobilization, there exist the steering committee composed of leaders of the partner organization and the technical working group. The model adopted is one of the models proposed by Ronie (2014) as potential models for collaboration in a partnership. However the relationship and hierarchy of authority within this structure is not well defined.

The study identified that the complex consortium's organizations structure hindered its effective implementation. They argued that its nature coupled with unclear lines of relationship and authority, facilitated delays in decision making processes and coordination of tasks. This is supported by Lynch (2009) who state that coordinating the activities of organizational units is accomplished mainly through positioning them in the hierarchy of authority. Pearce and Robinson (2011) noted that structure and strategy have to be interrelated for the success of the organization. The study established that consortium organizational structure should be reviewed to accommodate new projects and new tasks that come with them, the composition of the steering committee should also be enhanced and the role of the secretariat well stated.

The study established that poor organizational culture challenged effective consortium operation. Therefore, this is supported by Friedman et al. (2014) who argue that culture affects not only the way employees behave and interact within an organization but also the decisions they make towards executing task and the organization's relationships with the external environment. Different partners in the consortium have different embedded values and beliefs rooted in their organizational history, and creating harmony was a milestone. As suggested, the management should strive to harmonize different cultures to ensure that some values were shared across the consortium partners to mitigate change resistance. 
The study found out that while the strategy selected may be sound, the implementation procedures, policies and systems could be flawed. With this, efforts to execute strategy are impaired. This is in line with Jones et al. (2010) who argue that creating an interface between new standard policies and approaches and existing systems build coherence and reduce complexities of managing local systems is normally a challenge in partnership. The study found out that the operational policies and procedures were not updated with the inception of the consortium. It was established that ViAgroforestry, Kenya has some aspects in the existing human resource policy that were not coherent with the current human resource practice in the strategy. The study found out that consortium would only achieve its intended objectives when the operational systems and procedures were reviewed, well integrated and implemented.

Resource Insufficiency was another consortium strategy implementation challenge that the study established. It was established that this may be as a result of lack of resources which included financial and human or physical resources. Established organizations may experience changes in the business environment that can render them commit or invest in new resources or incur higher cost than were expected (Pearce and Robinson, 2011). The partners in the consortium had different resource requirements, customers and stakeholders require different funding arrangements to deliver investments. Some partners had well established offices and other systems while others needed to put these systems in place. Other thematic areas required more financial resources to implement, for example KERUSSU LTD undertook a lot of capacity building on financial services and its budget was always higher than other partners. The study suggested that ViAgroforestry Kenya should develop a resource allocation process model that would put into consideration all these dynamics. The resource funding base could be diversified to complement the existing ones.

The study also identified that poor communication was an impediment to consortium strategy implementation. Communication channels, methods and tools adopted by an organization are normally outlined in a given strategy. It is normally seen as lifeblood of an organization enhancing coordination, decision making and feedback. This is in line with Luthans (2011) who argue that enhanced communication process ensures proper coordination and management of day to day activities. It was evident that some staffs and stakeholders normally did not have opportunity to attend consortium meetings therefore were not well informed about the consortium strategy direction. They were parties to the consortium but they felt not being involved fully negating their contribution. This is in line with Kagumba (2014) who found out that lack of proper stakeholder involvement impeded strategy implementation at ViAgroforestry, Kenya. 
The study established that lack of management support impeded consortium strategy implementation. The top management often did not consult, followed the guidelines or directed staffs to subject some partners to organizational capacity assessment to ascertain the gaps before admitting them into the consortium. This is in line with Abuya (2013) who observed that most organizations are unable to implement their strategies due to non-commitment of top management. These partners had weak systems to manage the proposed projects and the budgets. The study suggested that the top management should support and reinforce the implementation guidelines and also adopt democratic styles in making decisions relating to consortium.

The study established that consortium strategy implementation was challenged by external environmental factors which included political, socio cultural, economic and technological in nature. This is because there is no organization that exists in isolation and these changes are interactive and can influence delivery and performance of programme activities. This is in line with Charity Commission, 2010; Maria et al., 2014; and Walther, 2015 who argue that the changing social environment compels organizations to align their social values, behaviors, attitudes lifestyle, work ethics, gender and social responsibilities to meet societal expectation. The study revealed that cultural aspects such as gender perceptions, religious values among the target group affect consortium operations.

On theory, the study found that organizations actions are contingent upon the internal and external factors to create the best fits in any given situation (Luthans, 2011). This study is in support of this theory as the smaller organizations that are part of the larger organization survive because the larger organizations they are part of cushions them (Wanjiru, 2015). Contingency theory emphasizes that there is no one best way to organize cooperation however contingency factors determine the organizations success. Conformity to existing values and traditions would lead to the loss of perspective of the new strategy which they said could result to delays, waste of resources and time loss, and of course loss of institutional memory. The interviewees argued that the integration with partners posed a big challenge that required a lot of innovativeness to overcome. The study supports the Mc Kinsey $7 \mathrm{~S}$ Framework that states that strategy, structure, systems, shared values, staffs, skills and style internally determines strategy implementation however this cannot be used in isolation.

The desk review conducted from the consortium operational guidelines revealed that good communication was a key ingredient to dialogue and enhancing relationship with the stakeholders however primary data revealed that the use of appropriate communication methods, tools and techniques were not fully exploited prompting stakeholders who are parties to the consortium 
to feel that without consultation their views were being excluded hence not fully involved in the consortium implementation process.

The empirical evidence revealed that there were no common standards (Monitoring and Evaluation System) for measuring results and performance of the consortium. However desk review of the operational guideline document revealed that the consortium ought to have common standards of monitoring progress fed with the data from partners individual monitoring systems. Partners ought to have individual monitoring systems but the consortium should develop and operationalize a common tool that monitors their performance collectively. This lack of common standard and inbuilt $\mathrm{M} / \mathrm{E}$ system was cited as a challenge revealing that the operational guidelines were not fully implemented, reviewed and reinforced.

During desk top review, the study obtained that the consortium had broad range of partners who were complementarily working towards common goals. The empirical evidence revealed that this composition could further enhance business practice if private sectors are brought on board to provide synergy on marketing components for partners pursuing value chain development approaches like Kimaeti (groundnuts), Miriu (banana) and Wetpa ( wood products). Hence it was suggested that the broad range of partnership along nonprofit entities could only be beneficial with incorporation of private sector organizations.

\section{Conclusion}

The findings indicated that ViAgroforestry, Kenya is geared towards achieving competitive advantage in an ever changing donor funded environment through implementation of consortium strategy. However for the organization to succeed, it was concluded that there should be adequate resources, updated and clear implementation guidelines, procedures and policies, open style of management, enhance staff competencies and skills, good organizational culture and simple organization structure. The organization should be aware and adjust promptly to the changes in the external environments.

Review of the consortium framework needs to be participatory, well communicated and understood among the stakeholders and the employees and even partners to enhance commitment and performance. Consortium is a key strategy to achieving objectives at a greater scale in a wider geographical coverage therefore understanding of the political, economic, social, legal and technological factors that affect consortium strategy implementation is required. Resource mobilization should be inbuilt to sustain project activities. Once resources have been mobilized ViAgroforestry, Kenya should follow laid down guidelines to guide utilization of funds. 
Indeed it can be concluded that ViAgroforestry Kenya would only realize and sustain its competitive edge in the environment by through this partnership approach by dealing with the established challenges through change of attitudes among staffs and managers in perceiving and embracing partnership. For enhanced resource mobilization, private sectors should be brought on board as partners to enrich synergy in business practice and also fade away the donor dependency syndrome such that implementation approaches incorporate social enterprises that are income generating. Norms for engagement in partnership should be clearly reinforced and respected by all regardless of the institutional history.

\section{Recommendations for Policy and Practice}

The study established that existing organizational culture did not support the consortium strategy implementation. Partners have different values, attitudes and beliefs embedded in their institutions history. The different cultures have not been harmonized and institutionalized within the consortium operations. Therefore the study recommends that ViAgroforestry and the partners create and promote a culture that is aligned to the consortium strategy to ensure effective implementation.

It was established that there was inadequate resources to implement and sustain consortium operations. Therefore, the study recommends that ViAgroforestry should create and institutionalize resource mobilization function within the partnership to ensure structured resource mobilization within the partnerships. Financial management policies should be reinforced within to ensure accountability and reduce misallocations.

The study established that the complex structure of the consortium challenged consortium strategy implementation. The study therefore recommends that the structure is reviewed and made simpler to reduce hierarchy to ease supervision, task allocations, coordination and decision making. The composition of the steering committee should also be reviewed to include the representatives from the board of directors from partner organizations.

The study established that the top management was not open to consultation and assessment while recruiting some partners into the consortium neither did they adhere to set criteria (due diligence) for selection. Therefore, the study recommends participatory review and reinforcement of consortium operational, guidelines and policies and open management approach towards recruiting partners into the consortium.

\section{Limitations of the Study}

After evaluating the results of this study, the following limitations that took conceptual, contextual, and methodological manifestations were 
encountered. Conceptually, the study only focused on challenges affecting consortium strategy implementation at ViAgroforestry, Kenya and not an evaluation of the strategy's performance.

Contextually, the study was limited to ViAgroforestry, Kenya, of which these findings may not represent ViAgroforestry as an organization that operates regionally in Uganda, Tanzania and Kenya with its headquarters in Nairobi, with three different consortia. The context of ViAgroforestry would look at the three different consortia operated within the region bringing more insights and diversity.

Methodologically, this study relied on employees of ViAgroforestry, Kenya, and in the absence of the researcher, these questions could have been answered by other staff, who might not be actively involved in the consortium strategy implementation process, thus creating a source of biasness. There were also ethical issues that emerged whereby the interviewees asked whether the verbatim would be quoted outside the study context. The researcher assured them of confidentiality and that the responses would only be used for study purposes. The study adopted case study methodology with data analyzed through content analysis that analyze data qualitatively compared to quantitative analysis that is more specific and accurate.

\section{Suggestions for Further Research}

The general perception is that, there is no research that is an end to itself. Rather, there will always be limitations in every research undertaking. Therefore based on the conceptual, methodological and contextual limitations that the study had established and highlighted, the researcher offers the following suggestions to direct future researchers. Future research should consider evaluating the performance of consortium strategy implementation at ViAgroforestry, Kenya. Thus establishing a linkage between consortium strategy implementation and performance, this will address the conceptual gap that the study found out.

There is also a need to carry out the study regionally to identify the challenges of implementing consortium strategy at ViAgroforestry. This will enable future researchers to compare whether the findings from ViAgroforestry, Kenya consortium can truly be reflected in ViAgroforestry, Uganda and Tanzania consortiums respectively and the dynamics interpreted at the regional level. Replication of this study should be done after some time to find out whether there are any changes that have taken place. These suggestions will address contextual gap that the study established. 


\section{References:}

1. Abuya, O. (2013).Challenges of Strategy Implementation at Kenya Aids Non Governmental Organizations Consortium: (Unpublished MBA Project), School of Business, University of Nairobi.

2. Alford, J., \& O’Flynn, J. (2012). Rethinking public service delivery: managing with external providers, Palgrave Macmillan, London.

3. Anne, B. P. \& Tom, C. (2012). Partner Power: A study of two distance education consortia, International Review of Research in Open and Distance Learning, Vol.7

4. Barney, J. (2010). Gaining and Sustaining Competitive Advantage. Upper Saddle River, N.J.: Financial Times/Prentice Hall.

5. Beerkens, H. (2014) .Global Opportunities and Institutional Embeddedness; Higher Education Consortia in Europe and Southeast Asia. Enschede: CHEPS.

6. Brennan, K. (2008). Working in a Consortium: A guide for third sector organisations involved in public service delivery (1st ed.). United Kingdom. Retrieved from https://www.buckscc.gov.uk

7. Catherine, B. \& Tom, F.( 2015). Creative People and Places; Governance and Consortium Working.

8. Carroll, A. \& Boletus, A. (2014). Business and Society: Ethics, Sustainability, and Stakeholder Management .9th Revised edition. South-Western College Publishing.

9. Charity Commission, (2010). Consortia for delivery of public service; the issues for small and medium sized charities Available at: http://digitalscholarship.unlv.edu/lib_articles/392

10. Chille, R. (2012). Implementing a New Integrated Library Management System in a Public Library Consortium, A case study on strategies for effective staff training to the school of information management,(Unpublished Msc Project) school of Information studies, Victoria University, London.

11. Christianson, J.B.,Moscovice, I.S., Johnson J., Kralewski J., \& Grogan, C. (2012) Evaluating rural hospital consortia: Health Affairs Vol 9. (1990):135-147 doi:10.1377/hlthaff.9.

12. Douglas, S., Flinchbaugh, M., Kruse, T., \& Ohler, L.A., (2009). The Benefits and Challenges of Acquisitions in a Consortium. Against the Grain: Vol. 21: Iss. 4, Article 31. DOI: http://dx.doi.org/10.7771/2380-176X.2462

13. Dawson, C. (2009). Introduction to research methods: A Practical guide for anyone undertaking a research project. Oxford: How to Books Ltd. 
14. Fiedler, F. (1964). A Theory of Leadership Effectiveness in Management. Mcgraw-Hill

15. Freeman, R.E. (1984). Strategic Management: A Stakeholder Theory' Journal of Management Studies 39(1): 1-21

16. Franco, M.S. (2014). Ohio's Third Grade Reading Guarantee, A Case Study of a Funded Consortium's Efforts. Columbus: Ohio. Education Research Center.

17. Friedman, B., Lynette,C., \& LeBan, K. (2014). Consortium Management and Leadership Training Facilitator's Guide. CORE Group: Washington D.C

18. Gonsalves, A. (2014). Lessons learned on Consortium-Based Research in Climate Change and Development. CARIAA Working Paper no. 1. International Development Research Centre, Ottawa, Canada and UK Aid, London, United Kingdom. Available online at: www.idrc.ca/cariaa

19. Hargrove, T., \& Hill, W. (2014). Southern Food Systems Education Consortium: Initiative for Future Agriculture and Food Systems Project. (Unpublished Paper), College of Agriculture, Environment and Nutrition Science, Tuskegee University, Tuskegee, AL.

20. Jones, M., Evans, S. \& Kimberlee, R. (2010). South West Well-being ProgrammeLearningfromConsortiumWorking,[Online],Available:htt p://www.cles.org. uk/wpcontent/uploads/2011/03/SW WB EffectiveConsortium-eAW.pdf

21. Kagumba, E. (2014). Stakeholder Involvement in Strategy Implementation, a Case of ViAgroforestry, Kenya. (Unpublished MBA Project). School of Business, University of Nairobi, Kenya.

22. Kothari, C. (2007). Research Methodology. New Delhi: New Age International (P) Ltd.

23. Luthans, F. (2011). Organisational Behaviour: An Evidence Based Approach (12th ed.). New Delhi: McGraw Hill.

24. Lynch, R. (2009). Strategic Management, 7th edn. Pearson Education Limited.

25. Maddrey, G., Gerland, A., Lee, C., \& Corapi, G. (2015).Consortium Model Networks: Evaluating the Potential of Collaboration (1st ed.). The Chartis Group Retrieved from http://www.chartis.com/whitepapers/evaluating the potential of collaboration through consortium model networks

26. Maria, B. A. \&Marmol Y.J. (2014). Academic Library Consortia in the Philippines: hanging in the balance. Library Management, 35(1/2), 15-36. http://dx.doi.org/10.1108//m-04-2013-0028 
27. Mugenda, O. \&Mugenda, A. (2007).Research methods: Qualitative and Quantitative Approaches. Nairobi, Kenya: African Centre for Technology Studies.

28. Pearce, J. \& Robinson, R. (2011).Strategic Management (12th ed.). Homewood III.: McGraw Hill.

29. Peters, T. \& Waterman, R. (1982).In search of excellence. New York: Harper \& Row.

30. Polonsky, M. \& Waller, D. (2005). Designing and Managing a Research Project. Thousand Oaks, Calif.: Sage Publications.

31. Ronnie, G. (2014). The consortium approach existing opportunities and best practice, Human resources for health: Sight savers International, Canada.

32. Ritchey, C. (2010). How the Liberia WASH Consortium Emerged and Evolved: School of Applied Sciences (Unpublished Msc Paper), Cranfield University. Cranfield, Liberia

33. Sternberg, E. (2004). Corporate governance: Accountability in the Marketplace. 2nd edition, The Institute of Economic Affairs, London.

34. Scott, W. (1995). Institutions and Organizations. Thousand Oaks: SAGE.

35. Tinoco, J. K., \& Sherman, B. W. (2014). Something Old is new Again: Airline- Airport Consortia and Key Stakeholder Benefits. World Review of Intermodal Transportation Research,5(1). http://dx.doi.org/10.1504/WRITR.2014.065039

36. Updegrove, A. (2016). Dissecting the Consortium: a Uniquely Flexible Platform for Collaboration. Standards Today, VolIX(1).

37. Walther, M. (2015) .Cooperation in the form of Consortia-Evaluation of risks and opportunities and criteria for the selection of business partners. Institute of Economic Studies, London.

38. Wanjiru, G. (2015). Working in a NGO consortium; Brien Holden Vision Institute East Africa: Child Eye Health Project.

39. Webster, J. (2010). Short-Term Study of the Liberia WASH Consortium model as a means of aid delivery in the transition from emergency to development. Cranfield University, Liberia WASH Consortium, Liberia.

40. Wharton, S. A., Counihan, H., \& Strachan, C. (2014). Implementing integrated community case management: stakeholder experiences and lessons learned in three African Countries. Sage Publications

41. Vi Agroforestry, (2015). Farmer Organisations Agroforestry Project Annual Report 2015 (Report No.4). ViAgroforestry Kenya. Available online; www.viagroforestry.org

42. Vi Agroforestry, (2011). Strategic Plan Report 2011-2015. ViAgroforestry 
43. Zikmund, W. G., Babin, B. J., Carr, J. C., \& Griffin, M. (2010). Business Research Methods. ( $8^{\text {th }}$ Edn). Mason HO: Cengage Learning 